Article

\title{
Yeast Diversity Associated with the Phylloplane of Corn Plants Cultivated in Thailand
}

\author{
Parichat Into ${ }^{1}$, Ana Pontes ${ }^{2}$, José Paulo Sampaio ${ }^{2, *(\mathbb{D})}$ and Savitree Limtong ${ }^{1,3, *(D)}$ \\ 1 Department of Microbiology, Faculty of Science, Kasetsart University, Bangkok 10900, Thailand; \\ parichat_into@hotmail.com \\ 2 UCIBIO-REQUIMTE, Departamento de Ciências da Vida, Faculdade de Ciências e Tecnologia, \\ Universidade Nova de Lisboa, 2829-51 Caparica, Portugal; ap.pontes@fct.unl.pt \\ 3 Academy of Science, The Royal Society of Thailand, Bangkok 10300, Thailand \\ * Correspondence: jss@fct.unl.pt (J.P.S.); fscistl@ku.ac.th (S.L.); \\ Tel.: +351-21-294-8530 (J.P.S.); +66-2-562-5444 (ext. 646626) (S.L.)
}

Received: 10 December 2019; Accepted: 6 January 2020; Published: 7 January 2020

\begin{abstract}
The ecology and diversity of phylloplane yeasts is less well understood in tropical regions than in temperate ones. Therefore, we investigated the yeast diversity associated with the phylloplane of corn, an economically important crop in Thailand, by a culture-dependent method. Thirty-six leaf samples were collected and 217 yeast strains were isolated by plating leaf-washings. The strains were grouped by PCR-fingerprinting and representative strains were identified by analysis of the D1/D2 domain of the large subunit rRNA gene. In total, 212 strains were identified within 10 species in the Ascomycota and 32 species in the Basidiomycota. Five strains represented potential new species in the Basidiomycota, one strain was recently described as Papiliotrema plantarum, and four strains belonged to the genera Vishniacozyma and Rhodotorula. A higher number of strains in the Basidiomycota (81.6\%) was obtained. Hannaella sinensis was the species with the highest occurrence. Principal coordinates analysis ordinations of yeast communities revealed that there were no differences in the similarity of the sampling sites. The estimation of the expected species richness showed that the observed species richness was lower than expected. This work indicated that a majority of yeast associated with the phylloplane of corn plant belongs to the phylum Basidiomycota.
\end{abstract}

Keywords: yeast; phylloplane; corn leaf; biodiversity

\section{Introduction}

The phylloplane corresponds to the surface or aboveground parts of plants [1]. Since leaves are the main constituent of the aerial portion of plants, they are viewed as an equivalent of the term phylloplane [2,3]. The phylloplane has been recognized as an important habitat for microorganisms, including bacteria, yeasts and filamentous fungi. The growth of phylloplane microorganisms is dependent on organic substances from plant exudates and inorganic substances present on the leaf surface [4,5]. Moreover, the microbial communities of the phylloplane are dependent of several factors like environmental factors, leaf age, particular growing conditions of the plant, and on the type and density of competing microorganisms $[3,6,7]$. The phylloplane of plants is colonized by several yeasts of the phyla Ascomycota and Basidiomycota [8-22].

In Thailand, rice, sugarcane and corn are crops of major economic relevance used for animal feed (Office of Agriculture Economics, Ministry of Agriculture and Cooperatives of Thailand). The corn cultivation area in 2016 and 2017 was approximately 1.0 and 1.1 million hectares, respectively, and corresponded to the production of 4.1 , and 4.8 million tons of corn, respectively. A better knowledge of the corn microbiome, which includes its phylloplane, is of relevance and could have practical 
implications, such as allowing the design of environmentally friendly biocontrol strategies against corn most relevant pathogens.

The phylloplane yeast community has been studied by both culture-dependent and culture-independent approaches. Recent studies addressed the topic of yeast diversity on the phylloplane of economically relevant crops and both culture-dependent and culture-independent approaches have been employed [13-22]. As observed for other microbes, the species composition of the yeast communities is not identical when the two approaches are compared or when culture-dependent approaches employ different yeast isolation techniques [16-21,23].

There are some reports of phylloplane yeasts in tropical regions and for Thailand the number of such studies has increased substantially in recent years. The phylloplane yeast diversity of the three crops mentioned above (rice, sugarcane and corn) was assessed by culture-dependent and culture-independent approaches [19-23]. However, the assessment of corn phylloplane yeasts was performed only by a culture-independent approach [22]. For rice phylloplane, a culture-dependent approach using enrichment isolation technique was performed [19] and a higher number of species of the Ascomycota was detected, by comparison with representatives of the Basidiomycota. This was in contrast with an assessment by a culture-independent approach that yielded the opposite results [20].

The particular environmental factors operating in different geographic and climatic regions can affect the microbial communities of the phylloplane [24]. Independent studies have suggested that the availability of nutrients, which is dependent on leaf age and growing conditions, can be of relevance for the composition of the yeast communities $[3,6,7,25]$. Glushakova and Chernov [26] also reported the seasonal changes in the number and species composition of yeast communities in the phylloplane.

The objective of this study was to assess the diversity of yeasts in an economically important crop, the phylloplane of corn plants in Thailand, by using a culture-dependent approach consisting of plating leaf washings for yeast isolation and subsequent molecular identification. Yeast strains were grouped by PCR-fingerprinting with minisatellite-specific oligonucleotides derived from the core sequence of bacteriophage M13, and representative strains of each profile were identified by analysis of the sequence of the D1/D2 domain of the large subunit (LSU) rRNA gene and the complete internal transcribe spacer (ITS) region.

\section{Materials and Methods}

\subsection{Samples and Yeast Isolation}

A total of 36 samples of green and healthy leaves of corn (Zea mays Linn.) for animal feed were collected in cultivation fields from 15 districts (sampling sites) in four provinces in Thailand (Figure 1) between July 2016 and October 2016 (Table 1). Each sample was a composite sample consisting of at least five leaves collected from different corn plants in a small area. Leaves were kept in plastic bags and stored at $8{ }^{\circ} \mathrm{C}$ and yeast isolation was carried out within 3 days after collection.

Yeasts were isolated by plating of leaf washings as described by Surussawadee et al. [27]. Each composite sample ( $3 \mathrm{~g}$ from all the collected leaves in each sample) was suspended in $50 \mathrm{~mL}$ of sterile $0.85 \%$ saline solution in a $250 \mathrm{~mL}$ Erlenmeyer flask and shaken on a rotary shaker at $25^{\circ} \mathrm{C}$ for $1 \mathrm{~h}$ to detach yeast cells from leaf surface. An aliquot of $0.1 \mathrm{~mL}$ of the washing solution was then spread on yeast extract-malt extract $(\mathrm{YM})$ agar $(0.3 \%$ yeast extract, $0.3 \%$ malt extract, $0.5 \%$ peptone and $2.0 \%$ agar $)$ supplemented with $0.025 \%$ sodium propionate and $0.02 \%$ chloramphenicol to inhibit filamentous fungi and bacteria, respectively. The plates were incubated at 20 and $25^{\circ} \mathrm{C}$ until yeast colonies appeared. For each sample, three replicates were investigated and yeast colonies of different morphologies were picked and purified by cross-streaking on YM agar. For each sample, similar yeast colonies grown at $20^{\circ} \mathrm{C}$ and $25^{\circ} \mathrm{C}$ were treated as one strain. Purified yeast strains were suspended in $\mathrm{YM}$ broth supplemented with $10 \% v / v$ glycerol and maintained at $-80^{\circ} \mathrm{C}$. 
Table 1. Corn leaf samples and correspondent number of strains isolated during this study.

\begin{tabular}{|c|c|c|c|c|c|c|c|}
\hline \multirow[b]{2}{*}{ Site } & \multicolumn{5}{|c|}{ Sampling } & \multirow{2}{*}{ No. of Sample } & \multirow{2}{*}{ No. of Strain } \\
\hline & Province District & Location & Date (dd mm yy) & Atmospheric Temperature a $\left({ }^{\circ} \mathrm{C}\right)$ & Rainfall $^{\mathrm{b}}(\mathrm{mm})$ & & \\
\hline & Suphan Buri & & & \multirow{5}{*}{$29.2-29.8$} & \multirow{5}{*}{$100.2-157.0$} & & \\
\hline $\mathrm{S} 1$ & Doembangnangbuat & $\begin{array}{l}14^{\circ} 50^{\prime} 27.1^{\prime \prime} \mathrm{N} \\
100^{\circ} 07^{\prime} 51.5^{\prime \prime} \mathrm{E}\end{array}$ & 2016-07-18 & & & 2 & 19 \\
\hline $\mathrm{S} 2$ & Sam Chuk & $\begin{array}{l}14^{\circ} 47^{\prime} 18.4^{\prime \prime} \mathrm{N} \\
100^{\circ} 09^{\prime} 14.1^{\prime \prime} \mathrm{E}\end{array}$ & $2016-07-30$ & & & 3 & 22 \\
\hline S3 & Nong Ya Sai & $\begin{array}{l}14^{\circ} 49^{\prime} 22.6^{\prime \prime} \mathrm{N} \\
99^{\circ} 55^{\prime} 46.0^{\prime \prime} \mathrm{E}\end{array}$ & 2016-08-06 & & & 2 & 9 \\
\hline \multirow[t]{3}{*}{ S4 } & Si Prachan & $\begin{array}{l}14^{\circ} 38^{\prime} 36.8^{\prime \prime} \mathrm{N} \\
100^{\circ} 08^{\prime} 53.1^{\prime \prime} \mathrm{E}\end{array}$ & 2016-08-06 & & & 2 & 13 \\
\hline & & & & & Total & 9 & 63 \\
\hline & Chai Nat & & & \multirow{5}{*}{$28.1-28.6$} & \multirow{5}{*}{$208.8-358.6$} & & \\
\hline S5 & Hankha & $\begin{array}{l}14^{\circ} 59^{\prime} 55.3^{\prime \prime} \mathrm{N} \\
100^{\circ} 05^{\prime} 45.6^{\prime \prime} \mathrm{E}\end{array}$ & 2016-08-06 & & & 4 & 22 \\
\hline S6 & Sankhaburi & $\begin{array}{l}14^{\circ} 57^{\prime} 37.8^{\prime \prime} \mathrm{N} \\
100^{\circ} 10^{\prime} 57.6^{\prime \prime} \mathrm{E}\end{array}$ & 2016-08-06 & & & 2 & 17 \\
\hline S7 & Manorom & $\begin{array}{l}15^{\circ} 23^{\prime} 11.6^{\prime \prime} \mathrm{N} \\
100^{\circ} 08^{\prime} 29.6^{\prime \prime} \mathrm{E}\end{array}$ & 2016-08-13 & & & 1 & 4 \\
\hline \multirow[t]{3}{*}{$\mathrm{S} 8$} & Sapphaya & $\begin{array}{l}15^{\circ} 08^{\prime} 15.5^{\prime \prime} \mathrm{N} \\
100^{\circ} 14^{\prime} 44.7^{\prime \prime} \mathrm{E}\end{array}$ & 2016-09-17 & & & 2 & 13 \\
\hline & & & & & Total & 9 & 56 \\
\hline & Nakhon Sawan & & & \multirow{5}{*}{$28.1-28.6$} & \multirow{5}{*}{374.7} & & \\
\hline S9 & Phayuha Khiri & $\begin{array}{l}15^{\circ} 28^{\prime} 06.3^{\prime \prime} \mathrm{N} \\
100^{\circ} 12^{\prime} 17.7^{\prime \prime} \mathrm{E}\end{array}$ & 2016-09-16 & & & 4 & 19 \\
\hline $\mathrm{S} 10$ & Phaisali & $\begin{array}{l}15^{\circ} 38^{\prime} 20.6^{\prime \prime} \mathrm{N} \\
100^{\circ} 46^{\prime} 49.6^{\prime \prime} \mathrm{E}\end{array}$ & 2016-09-16 & & & 2 & 16 \\
\hline S11 & Tak Fa & $\begin{array}{l}15^{\circ} 21^{\prime} 21.2^{\prime \prime} \mathrm{N} \\
100^{\circ} 30^{\prime} 10.0^{\prime \prime} \mathrm{E}\end{array}$ & 2016-09-17 & & & 2 & 12 \\
\hline \multirow[t]{2}{*}{$\mathrm{S} 12$} & Takhli & $\begin{array}{l}15^{\circ} 16^{\prime} 19.5^{\prime \prime} \mathrm{N} \\
100^{\circ} 21^{\prime} 48.1^{\prime \prime} \mathrm{E}\end{array}$ & 2016-09-17 & & & 1 & 5 \\
\hline & & & & & Total & 9 & 52 \\
\hline & Phetchabun & & & \multirow{5}{*}{$27.2-27.8$} & \multirow{4}{*}{290.5} & & \\
\hline $\mathrm{S} 13$ & Bueng Sam Phan & $\begin{array}{l}15^{\circ} 43^{\prime} 51.0^{\prime \prime} \mathrm{N} \\
100^{\circ} 52^{\prime} 34.9^{\prime \prime} \mathrm{E}\end{array}$ & 2016-09-16 & & & 2 & 10 \\
\hline S14 & Mueang Phetchabun & $\begin{array}{l}16^{\circ} 18^{\prime} 08.2^{\prime \prime} \mathrm{N} \\
101^{\circ} 03^{\prime} 58.2^{\prime \prime} \mathrm{E}\end{array}$ & 2016-09-17 & & & 3 & 15 \\
\hline \multirow[t]{2}{*}{ S15 } & Chon Daen & $\begin{array}{l}16^{\circ} 12^{\prime} 32.6^{\prime \prime} \mathrm{N} \\
100^{\circ} 57^{\prime} 48.9^{\prime \prime} \mathrm{E}\end{array}$ & 2016-09-17 & & & 4 & 21 \\
\hline & & & & & Total & 9 & 46 \\
\hline
\end{tabular}

${ }^{a}$ Range of atmospheric temperature obtained in particular month of sampling area. ${ }^{b}$ Range of rainfall obtained in particular month of sampling area. 


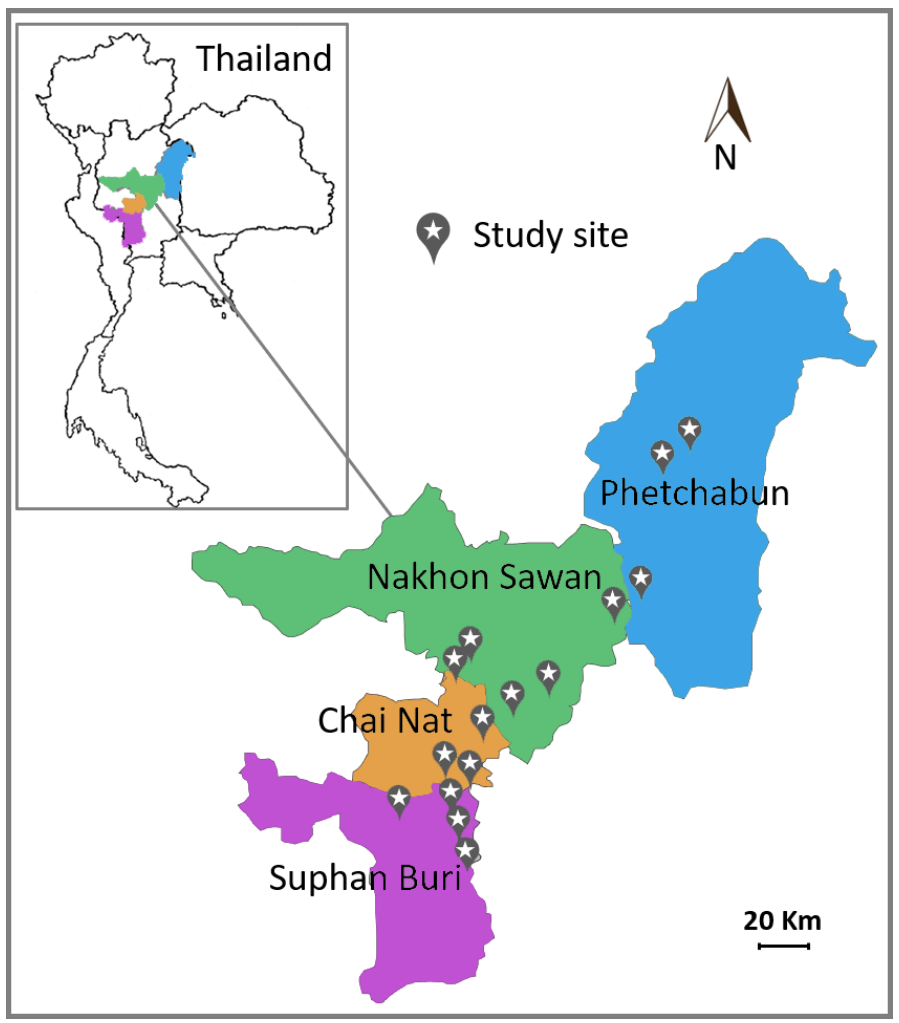

Figure 1. Map of sampling sites in four provinces in Thailand.

\subsection{Yeast Identification}

DNA extraction and purification followed the protocols of Yurkov et al. [28,29]. In brief, DNA was isolated from 3-4 days old cultures. The cells were extracted by the combined physical and chemical methods. The cells were mixed with glass beads and stored at $-20^{\circ} \mathrm{C}$ for at least one hour and Tris-ethylene-diamine tetracetic acid (TE)-phenol and chloroform was added. The cells were disrupted by vortexing for $20-25 \mathrm{~min}$ and centrifuged at $4{ }^{\circ} \mathrm{C}$. The DNA was purified by ethanol precipitation and was then dissolved in $50 \mu \mathrm{L}$ of TE buffer containing $10 \mu \mathrm{g} / \mathrm{mL}$ RNAse (Sigma-Aldrich, St. Louis, MO, USA).

PCR-fingerprinting with minisatellite-specific oligonucleotides (STAB Vida Inc., Lisbon, Portugal) derived from the core sequence of bacteriophage M13 was used to group yeast strains [30]. Strains showing identical electrophoretic profiles were considered as conspecific and one to two representatives of each PCR fingerprinting group were subjected to sequencing of the D1/D2 domain and ITS region. DNA fragments were amplified by PCR using the primers ITS1f and NL4 [31,32]. The PCR condition were as described by Yurkov et al. [29]. PCR products were purified with GenElute PCR Clean-Up Kit (Sigma-Aldrich, USA) and the purified products were submitted to STAB Vida Inc. (Portugal) for Sanger dideoxy sequencing with ABI 3730 xl sequencer (Applied Biosystems, Foster City, CA, USA).

For yeast identification, the nucleotide sequences obtained in this study were compared with sequences deposited in the NCBI (www.ncbi.nih.gov) and CBS (www.westerdijkinstitute.nl) databases. For identification of ascomycetous yeasts, strains with 0-3 nucleotide differences in the D1/D2 domain were treated as conspecific and strains showing greater than $1 \%$ nucleotide substitutions were considered to be different species [33]. When necessary, the "potential new species" designation was used. For the identification of basidiomycetous yeasts, strains differing by two or more nucleotide substitutions were considered to represent different species. When necessary, complete ITS sequences were also analyzed following the previous study [34] in order to assist the D1/D2-based identifications. 


\subsection{Phylogenetic Analysis}

Phylogenetic analyses based on the sequences of the D1/D2 domain of the LSU rRNA gene were used to confirm the yeast identification results. Sequences of the type strains of relevant species were obtained from the NCBI database. The sequences were aligned with MUSCLE software version 3.6 [35], provided in MEGA version 7.0 [36]. A phylogenetic tree was constructed from the estimated evolutionary distance data using the general time reversible (GTR) model and the Maximum likelihood method and was performed in MEGA version 7.0. Bootstrap values were determined from 1000 random re-samplings [37].

\subsection{Biodiversity Analyses}

The measure of similarity by the classical Jaccard similarity coefficient (based on species absence or presence) was used in order to assess the similarities of the yeast communities in the samples collected in the 15 sampling sites. The calculation of the Jaccard similarity coefficient (Jaccard index) was performed using the PAST software version 3.25 [38]. The Principal Coordinates Analysis (PCoA) for the ordination of yeast communities in the 15 sampling sites was based on the Jaccard similarity index and employed the PAST software version 3.25 [38]. Species accumulation curves were calculated with EstimateS 9.1.0 using 100 randomizations. Three estimator of species richness were used i.e., Chao1 richness estimator, incidence-based coverage (ICE) estimators and bootstrap richness estimator with sample-based abundance data [39].

\section{Results}

\subsection{Sample Collection and Yeast Isolation}

From 36 leaf samples of corn for animal feed collected in cultivation fields in four provinces, Suphan Buri $(n=9)$, Chai Nat $(n=9)$, Nakhon Sawan $(n=9)$ and Phetchabun $(n=9)$ in Thailand, 217 yeast strains were obtained. As shown in Table 1 similar numbers of yeast strains were obtained in the different provinces, viz. 63, 56, 52 and 46 strains obtained from Suphan Buri, Chai Nat, Nakhon Sawan and Phetchabun, respectively.

\subsection{Yeast Identification}

PCR-fingerprinting with primer M13 of 217 strains yielded 101 profiles. From these profiles, 152 strains were selected for identification by sequencing the D1/D2 domain of the LSU rRNA gene and in some cases, the complete ITS region sequence was also used (Tables S2 and S3). The phylogenetic placement of the phylloplane strains is shown in Figure 2 (Ascomycota) and Figure 3 (Basidiomycota). The phylloplane yeasts were found to represent 45 species distributed in four main fungal lineages: Ascomycota, Saccharomycotina (10 species, 40 strains), Basidiomycota, Agaricomycotina (16 species, 80 strains), Basidiomycota, Pucciniomycotina (12 species, 48 strains) and Basidiomycota, Ustilaginiomycotina (7 species, 49 strains) (Table 2 and Table S1, Figures 2 and 3). Among the 45 species found, two species of the Rhodotorula (two strains) and Vishniacozyma (two strains) in the Phylum Basidiomycota are not yet formally described and therefore represent new species (Table S2). The known species of Basidiomycota were assigned to 15 genera: Anthracocystis (one species), Cystobasidium (one species), Dioszegia (one species), Dirkmeia (one species), Hannaella (six species), Kwoniella (two species), Moesziomyces (one species), Papiliotrema (four species), Rhodosporidiobolus (three species), Rhodotorula (one species), Saitozyma (one species), Sporobolomyces (four species), Symmetrospora (one species) and Ustilago (three species) (Table 2 and Table S1). Papiliotrema plantarum was recently described by us [40]. The ten Ascomycota species belonged to six genera: Candida (four species), Kodamaea (one species), Meyerozyma (one species), Metschnikowia (one species), Pichia (two species) and Wickerhamomyces (one species) (Table 2 and Table S1). According to the BLASTn search, the D1/D2 and ITS sequences of these four strains were similar to several sequences of unidentified species that are deposited in the GenBank database. The complete characterization of these sequences and strains will 
be necessary before the formal description of new species is proposed. The number of yeasts of the phylum Basidiomycota (81.6\%) was much higher than those assigned to the Ascomycota (18.4\%).

Table 2. Yeast species and respective frequencies detected on corn phylloplane.

\begin{tabular}{|c|c|c|c|c|c|c|}
\hline \multirow{2}{*}{ Taxa } & \multicolumn{4}{|c|}{ Number of Strain } & \multirow{2}{*}{ Total } & \multirow{2}{*}{ FO (\%) } \\
\hline & Suphan Buri & Chai Nat & Nakhon Sawan & Phetchabun & & \\
\hline \multicolumn{7}{|l|}{$\begin{array}{c}\text { Phylum Ascomycota } \\
\text { Subphylum Saccharomycotina }\end{array}$} \\
\hline Candida intermedia & 1 & 1 & 3 & - & 5 & 13.9 \\
\hline Candida quercitrusa & - & - & - & 1 & 1 & 2.8 \\
\hline Candida saopaulonensis & - & 2 & - & 2 & 4 & 11.1 \\
\hline Candida uthaithanina & - & 1 & - & - & 1 & 2.8 \\
\hline Kodamaea ohmeri & 1 & - & - & - & 1 & 2.8 \\
\hline Metschnikowia lopburiensis & - & 1 & 1 & 1 & 3 & 8.3 \\
\hline Meyerozyma caribbica & 2 & 3 & 5 & 4 & 14 & 38.9 \\
\hline Pichia bruneiensis & - & 2 & - & 4 & 6 & 16.7 \\
\hline Pichia kudriavzevii & 1 & - & 1 & - & 2 & 5.6 \\
\hline Wickerhamomyces anomalus & 2 & 1 & - & - & 3 & 8.3 \\
\hline \multicolumn{7}{|l|}{$\begin{array}{c}\text { Phylum Basidiomycota } \\
\text { Subphylum Agaricomycotina }\end{array}$} \\
\hline Dioszegia zsoltii & 1 & 1 & 1 & - & 3 & 8.3 \\
\hline Hannaella oryzae & - & - & 2 & - & 2 & 5.6 \\
\hline Hannaella pagnoccae & - & 2 & - & 1 & 3 & 8.3 \\
\hline Hannaella phetchabunensis & - & 1 & - & - & 1 & 2.8 \\
\hline Hannaella phyllophila & - & 1 & 1 & 1 & 3 & 8.3 \\
\hline Hannaella siamensis & 1 & 2 & - & 2 & 5 & 13.9 \\
\hline Hannaella sinensis & 5 & 8 & 6 & 5 & 24 & 66.7 \\
\hline $\begin{array}{l}\text { Potential new species closest to } \\
\text { Vishniacozyma heimaeyensis }\end{array}$ & 1 & 1 & - & - & 2 & 5.6 \\
\hline Kwoniella bestiolae & 1 & - & - & - & 1 & 2.8 \\
\hline Kwoniella heveanensis & - & 1 & - & - & 1 & 2.8 \\
\hline Papiliotrema flavescens & 1 & 5 & 2 & 6 & 14 & 38.9 \\
\hline Papiliotrema laurentii & 3 & 1 & 1 & - & 5 & 13.9 \\
\hline Papiliotrema rajasthanensis & 5 & 2 & 3 & 1 & 11 & 30.6 \\
\hline Papiliotrema ruineniae & - & 1 & 1 & - & 2 & 5.6 \\
\hline Plapiliotrema plantarum & - & 1 & - & - & 1 & 2.8 \\
\hline Saitozyma flava & 1 & - & - & 1 & 2 & 5.6 \\
\hline \multicolumn{7}{|l|}{ Subphylum Pucciniomycotina } \\
\hline Cystobasidium calyptogenae & 1 & - & - & - & 1 & 2.8 \\
\hline Symmetrospora vermiculata & 1 & 1 & 1 & - & 3 & 8.3 \\
\hline Rhodotorula mucilaginosa & 2 & - & - & - & 2 & 5.6 \\
\hline Rhodotorula paludigena & 5 & 4 & 5 & 4 & 18 & 50.0 \\
\hline Rhodotorula toruloides & - & - & 1 & - & 1 & 2.8 \\
\hline $\begin{array}{l}\text { Potential new species closest to } \\
\text { Rhodotorula toruloides }\end{array}$ & 1 & 1 & - & - & 2 & 5.6 \\
\hline Rhodosporidiobolus nylandii & 1 & - & - & - & 1 & 2.8 \\
\hline Rhodosporidiobolus ruineniae & - & - & 2 & 1 & 3 & 8.3 \\
\hline Rhodosporidiobolus fluvialis & - & 1 & - & - & 1 & 2.8 \\
\hline Rhodosporidiobolus odoratus & 1 & - & - & - & 1 & 2.8 \\
\hline Sporobolomyces blumeae & 5 & - & 2 & - & 7 & 19.4 \\
\hline Sporobolomyces nakasei & - & - & - & 6 & 6 & 16.7 \\
\hline Sporobolomyces carnicolor & - & 1 & - & 1 & 2 & 5.6 \\
\hline \multicolumn{7}{|l|}{ Subphylum Ustilaginomycotina } \\
\hline Anthracocystis elionuri & 1 & 3 & 2 & - & 6 & 16.7 \\
\hline Dirkmeia churashimaensis & 8 & 4 & 4 & 1 & 17 & 47.2 \\
\hline Moesziomyces antarcticus & 3 & - & 5 & 2 & 10 & 27.8 \\
\hline Ustilago trichophora & 1 & 1 & - & - & 2 & 5.6 \\
\hline Ustilago siamensis & 1 & - & - & - & 1 & 2.8 \\
\hline Ustilago sparsa & 6 & 2 & 3 & 2 & 13 & 36.1 \\
\hline
\end{tabular}

${ }^{a}$ FO; Frequency of occurrence (\%) was calculated as the number of samples, where a particular species was observed, as a proportion of the total number of samples. 


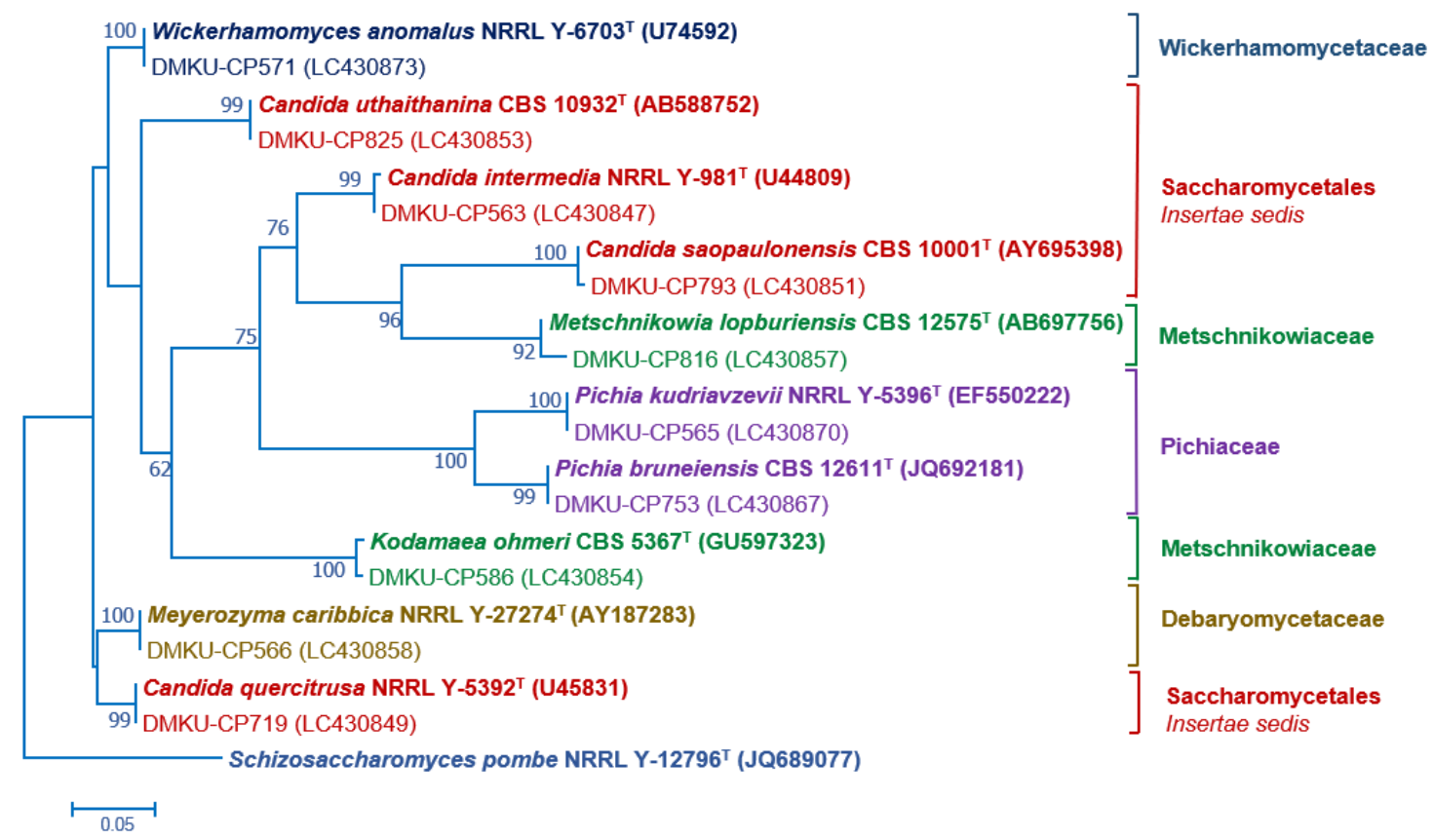

Figure 2. Phylogenetic placement of known species of corn phylloplane ascomycetous yeasts (Phylum Ascomycota, subphylum Saccharomycotina) based on the sequence of the D1/D2 region of LSU rRNA gene. Reference sequences retrieved from the GenBank database are included. The tree was constructed with the maximum-likelihood method and the GTR evolutionary model. Numbers on the branches represent the bootstrap values ( $>50 \%$ ) from 1000 random replicates. The scale bar corresponds to a genetic distance of 0.05 substitutions per position.

\subsection{Yeast Diversity}

Considering the strains isolated in this study, the number of yeasts of the phylum Basidiomycota $(81.6 \%)$ was much higher than those assigned to the Ascomycota (18.4\%). Hannaella sinensis was the species with the highest occurrence species, it was found in 24 samples out of 36 samples $(66.7 \%)$. The comparison of the similarity of the yeast community from each sampling sites was carried out in pairwise comparisons. It showed that the yeast species composition was different among all sampling sites. The similarity coefficient values were in the range of $0-0.57$ (Table S4). Globally we obtained an average value of 0.25 for the similarity between yeast communities, which could mean that the sampling sites shared, on average $25 \%$ of the species. A comparatively higher similarity (0.57) was observed between sampling site 14 (Mueang Phetchabun, Phetchabun, Thailand) and sampling site 15 (Chon Daen, Phetchabun, Thailand). On the opposite side, the comparison of similarity of the sampling site 4 (Si Prachan, Supahn Buri, Thailand) and sampling site 7 (Manorom, Chai Nat, Thailand) had a similarity index $=0$, and the same happened for the comparison between sampling site 7 (Manorom, Chai Nat, Thailand) and sampling site 11 (Tak Fa, Nakhon Sawan, Thailand). However, the PCoA plot based on Jaccard similarity indices suggested that the yeast communities of all sampling sites were in the same group and that there were no marked differences on the similarity on the sampling sites (Figure 4). The estimation of the expected species richness taking in consideration the sampling effort by the Bootstrap, Chao 1 and ICE estimators revealed that the observed species richness was lower than the expected species richness (Figure 5). 


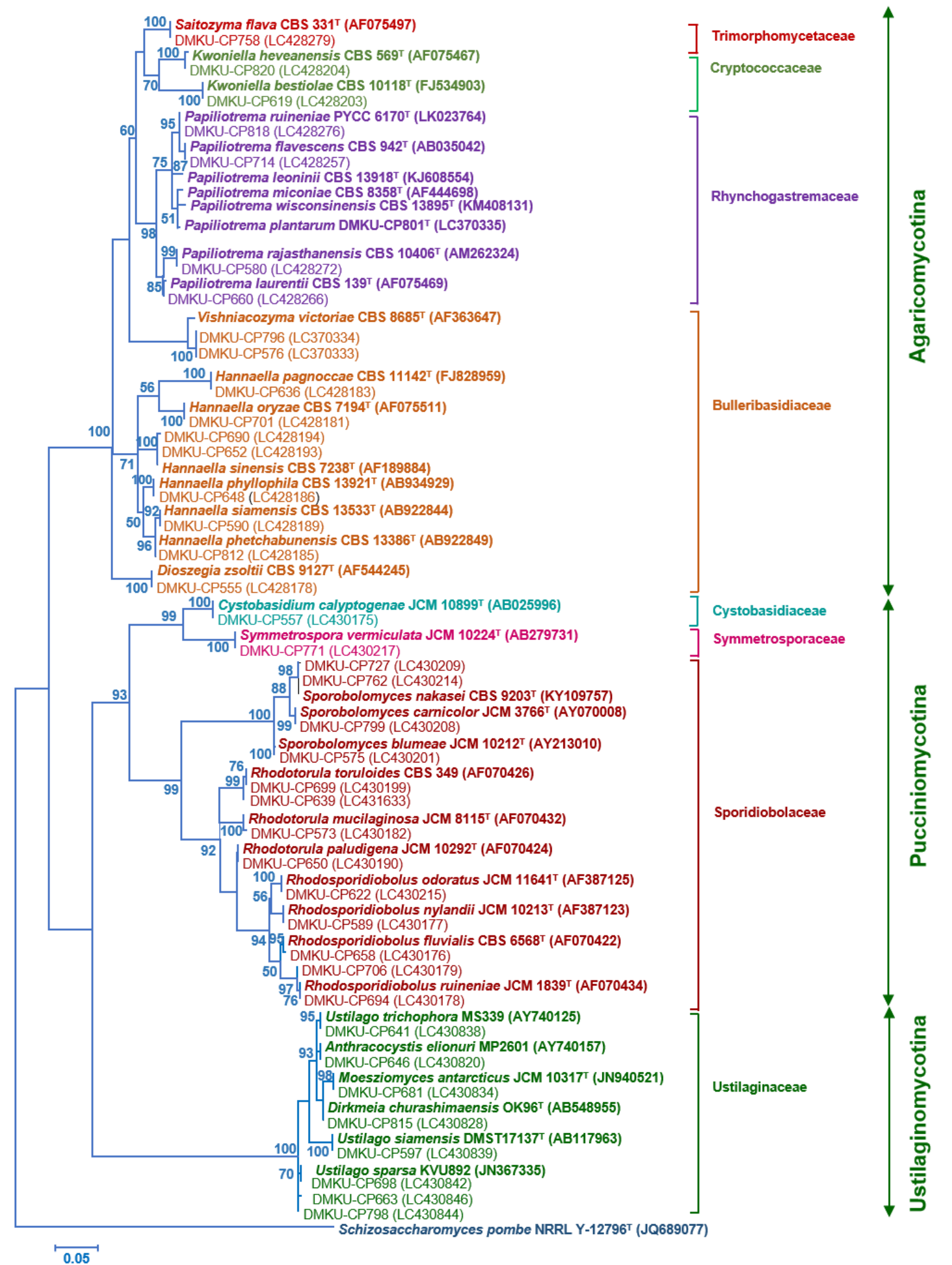

Figure 3. Phylogenetic placement of known species of corn phylloplane basidiomycetous yeasts (Phylum Basidiomycota: subphylum Pucciniomycotina, Ustilaginomycotina and Agaricomycotina) based on the sequence of the D1/D2 region of LSU rRNA gene. Reference sequences retrieved from the GenBank database are included. The tree was constructed with the maximum-likelihood method and the GTR evolutionary model. Numbers on branches represent the bootstrap values (>50\%) from 1000 random replicates. The scale bar corresponds to a genetic distance of 0.05 substitutions per position. 


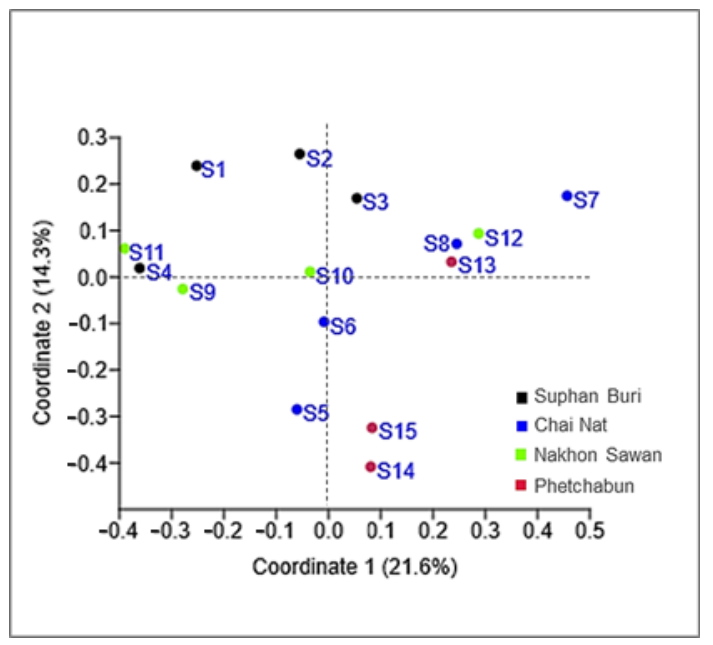

Figure 4. Principal Coordinate Analysis (PCoA) plots of corn phylloplane yeast communities in 15 sampling sites in Thailand, using the Jaccard similarity coefficient.

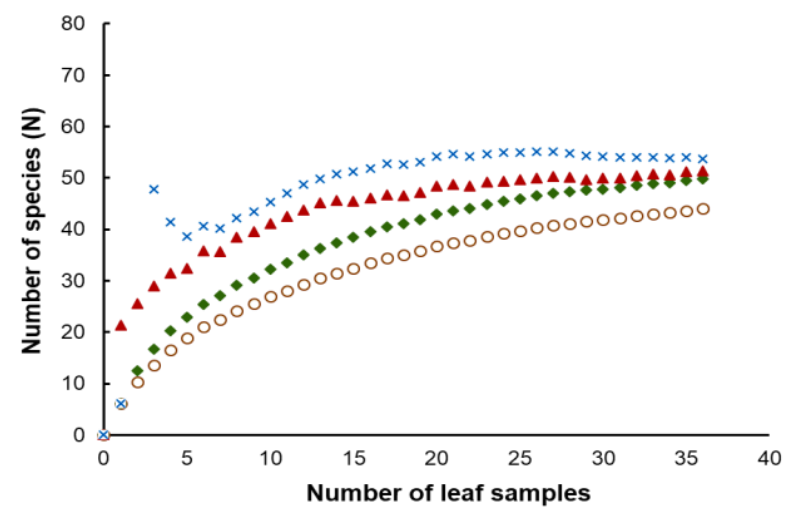

Figure 5. Observed (unfilled circle) curves and estimated phylotype richness of corn phylloplane yeast versus sample size using bootstrap (filled diamond), Chao 1 (filled triangle) and ICE (cross) estimators using sample-based abundance data.

\section{Discussion}

In this work, we employed a culture-dependent approach consisting on plating leaf washings to analyze the yeast community of corn phylloplane. We measured a much larger proportion of basidiomycetous yeasts $(81.6 \%)$ than the fraction of ascomycetous yeasts. This result is in accordance with our previous study of yeasts from the corn phylloplane using a culture-independent approach that showed that the majority (98.5\%) of yeast sequences belonged to the Basidiomycota [22]. Moreover, this result is in agreement with other studies that employed the culture-dependent approach, like that of de Azeredo et al. [8], who found that most of the detected yeast species belonged to the Basidiomycota $(92.2 \%)$. However, we found that species composition of the yeast community associated with corn phylloplane inferred with culture-dependent and culture-independent approaches is different. The same conclusion can be obtained in the comparison of results concerning analyses of the rice yeast community in Thailand [21,23].

In our study, basidiomycetous yeasts were found to belong to the three main lineages of the Basidiomycota: the Pucciniomycotina, Ustilaginomycotina and Agaricomycotina. The species with the highest occurrence species was Hannaella (Bullera) sinensis. This species was first described based on a strain obtained from a wheat leaf (Triticum sp.) in China [41] and later found to occur widely in the tissue and the leaf surface of various plants such as rice, corn, sugarcane, elephant grass, and cactus [20,42-47]. Dirkmeia churashimaensis, P. flavescens, P. rajasthanensis and R. paludigena, which were frequently found in this study, were also commonly found in the phylloplane of trees $[17,48,49]$. The 
species with the highest occurrence species found in this study (H. sinensis) is distinct from the most abundant species found in a culture-independent survey, that reported Pseudozyma hubeinsis pro tem. and Moesziomyces antarcticus as the species with the highest occurrence yeasts [22]. Moreover, 31 species detected in this study were not found when a culture-independent method was used (e.g., $M$. caribbica, $P$. flavescens, $P$. rajasthanensis and $R$. paludigena). On the other hand, 12 species found by a culture-independent method were not detected in this study (e.g., Moesziomyces aphidis, Meyerozyma rugulosus, Meyerozyma guilliermondii, Pseudozyma hubeiensis and Spencerozyma crocea) [22]. Although these two investigations were carried out in Thailand, they were performed in different seasons and in different geographic locations. In the present study, we collected the samples during the rainy season (June to October), while Nasanit et al. [22] collected samples between January and May, during the dry season. Such different sampling strategies might partly explain the different results. Also, the two studies were not performed in the same provinces, except for Suphan Buri and Nakorn Swan. de Azeredo et al. [8] assessed the diversity of phylloplane yeasts in sugarcane leaf in Brazil by plating of leaf-washings and found as prevalent species Debaryomyces hansenii, Naganishia albidus (formerly Cryptococcus albidus), Papiliotrema laurentii (formerly Cryptococcus laurentii) and Rhodotorula mucilaginosa, which differs considerably from the prevalent community found in corn in our study.

Another aspect previously documented [22,24,26] and supported by our studies, concerns the marked differences obtained in different seasons and geographic locations. It is relevant to note that in our study we have collected corn leaf samples in different growth stages and growing conditions of the plants, which may have affected the results. Also, the sampling site climatic condition, which relates with the sampling period of the study, leaf age and technique of investigation involved in the analysis of the yeast communities are also critical factors that need to be taken into consideration. Therefore, although our study illuminates phylloplane yeast diversity in corn leaves in a tropical region, further studies should aim at clarifying if species richness is affected by sampling locations, growing conditions and leaf age.

We obtained discrepant results between the comparison of species compositions among the sampling sites using the Jaccard similarity coefficient and the analysis using a PCoA plot. This result suggests that there is no significant spatial heterogeneity in what concerns the composition of the phylloplane yeast community. Moreover, since in this study we collected the samples only in the central part of Thailand, additional sampling in other locations should clarify the relationship between the yeast community composition and geography. The observed species richness was lower than the expected species richness. Overall, species richness estimators perform differently depending on the yeast community structure. An increase in the number of rare species results in higher species richness values predicted by the estimators (Bootstrap, Chao 1 and ICE), that distinguish between rare and frequent species. Our results suggest that rare yeast species were present in the community and that they remained unobserved. This result, and the failure to fully document the existing yeast diversity was also obtained in other similar studies [20-22,50]. It is possible that a more exhaustive sampling could have led to a more precise estimate of the actual yeast diversity indices.

Besides documenting the yeast diversity of corn phylloplane our study provides additional data to support the view that the technique of investigation involved in the analysis of the yeast communities, the choice of sampling sites, the climatic condition, which might relate to the sampling period of the study, and the plant species, all are critical factors that need to be taken into consideration when investigating the yeast diversity associated with the phylloplane.

In recent years, yeasts isolated from various natural habitats have been found to havepotential as effective producers of various biotechnological products worldwide. Various wild yeast species have been reported to have a vital role in modern industrial biotechnology, for example, for the production of citric acid [51], single cell proteins [52,53], ethanol [54,55], microbial oils [56-58], indole-3- acetic acid (IAA) [59], itaconic acid [60], glycolipid biosurfactants [49], arabitol [61], xylitol [62], erythritol and mannitol [63]. In this study, we isolated 217 yeast strains of 10 species in the Ascomycota and 35 species in the Basidiomycota. Some of these species have been reported to have industrial 
biotechnological potential. Candida intermedia, Candida tropicalis and Pichia kudriavzevii have been reported to produce ethanol and single-cell protein [52-55] whereas Wickerhamomyces anomalus has been found to have the ability to produce ethanol and xylitol [54,62]. Meyerozyma caribbica has exhibited potential for xylitol production [64]. Various species in the Basidiomycota found in this study including P. laurentii, R. paludigena, Rhodotorula toruloides, Rhodosporidiobolus fluvialis, Rhodosporidiobolus ruineniae and Sporobolomyces carnicolor have been reported for their potential in microbial lipid production [56-58]. Papiliotrema flavescens has been reported to be able to produce $\alpha$-galactosidase [65]. The strains of $R$. paludigena and $H$. sinensis also showed the ability to produce large qualities of indole-3-acetic acid (IAA) [59]. D. churashimaensis and M. antarcticus, which previously belonged to the genus Pseudozyma, have been applied for itaconic acid production [60]. Moreover, these two species and Ustilago (Pseudozyma) siamensis have been found to be capable of producing a mixture of mannosylerythritol lipids, which are glycolipid biosurfactants [49]. These findings suggest that some of the yeast strains isolated in this study could have potential for production of various industrial biotechnological products.

\section{Conclusions}

The result of this study revealed that a majority of yeasts on the phylloplane of the corn plant were in the phylum Basidiomycota when assessed by a culture-dependent method using the plating of leaf washings for yeast isolation, which was in accordance with assessment done by a culture-independent method. The finding of that basidiomycetous yeasts are dominant on the phylloplane of the corn plant is similar to what is found in other plant species. The yeast species with the highest occurrence was $H$. sinensis. Some species of corn phylloplane yeasts found in this study differed from those found in a study using a culture-independent method due to differences in the sampling period and to intrinsic biases of the two methods. To obtain a better characterization of the yeast community inhabiting the phylloplane, we suggest using a culture-dependent method based on direct isolation and employing different culture media in combination with a culture-independent approach. In addition, some of the yeast strains obtained in this study could have potential for application in industrial biotechnology.

Supplementary Materials: The following are available online at http://www.mdpi.com/2076-2607/8/1/80/s1, Table S1: Yeast species and isolates from corn leaf samples in each province, Table S2: Sequence similarity analysis of the D1/D2 domain of corn phylloplane yeasts and their closely related species, Table S3: Sequence similarity analysis of the ITS region of corn phylloplane isolates showing $\geq 2$ nucleotide substitutions in the D1/D2 region, Table S4: Similarity coefficient between yeast communities in pairwise comparisons based on the Jaccard similarity index.

Author Contributions: P.I. performed the data curation, formal analysis investigation, methodology and writing-original draft preparation. A.P. performed investigation and methodology, J.P.S. and S.L.; provided conceptualization, funding acquisition, project administration, resources, supervision, writing-review and editing. All authors have read and agreed to the published version of the manuscript.

Funding: This work was supported by the Thailand Research Fund through the TRF Research-Team Promotion Grant (RTA5480009 and RTA6080004) and the Royal Golden Jubilee PhD programme grant no. PHD/0025/2556, Thailand. This study was supported by FCT grant UID/Multi/04378/2013, Portugal.

Acknowledgments: The authors would like to thank Passorn Wonnapinij, Department of Genetics, Faculty of Science, Kasetsart university for her kind suggestion on biodiversity analysis.

Conflicts of Interest: The authors declare that they have no conflict of interest in the publication.

\section{References}

1. Whipps, J.; Hand, P.; Pink, D.; Bending, G.D. Phyllosphere microbiology with special reference to diversity and plant genotype. J. Appl. Microbiol. 2008, 105, 1744-1755. [CrossRef] [PubMed]

2. Phaff, H.J.; Starmer, W.T. Yeasts associated with plants, insects and soil. In The Yeasts, 2nd ed.; Rose, A.H., Harrison, J.S., Eds.; Academic Press: London, UK, 1987; pp. 123-180.

3. Fonseca, Á.; Inácio, J. Phylloplane yeasts. In Biodiversity and Ecophysiology of Yeasts; Rosa, C., Péter, G., Eds.; Springer Science: Berlin/Heidelberg, Germany, 2006; pp. 263-301. 
4. Fiala, V.; Glad, C.; Martin, M.; Jolivet, E.; Derridj, S. Occurrence of soluble carbohydrates on thephylloplane of maize (Zea mays L.): Variations in relation to leaf heterogeneity and position on the plant. New Phytol. 1990, 115, 609-615. [CrossRef]

5. Xin, G.; Glawe, D.; Doty, S.L. Characterization of three endophytic, indole-3-acetic acidproducing yeasts occurring in Populus trees. Mycol. Res. 2009, 113, 973-980. [CrossRef] [PubMed]

6. Andrews, J.H.; Harris, R.E. The ecology and biogeography of microorganisms on plantsurfaces. Ann. Rev. Phytopathol. 2000, 38, 145-180. [CrossRef] [PubMed]

7. Lindow, S.E.; Brandl, M.T. Microbiology of the phyllosphere. Appl. Environ. Microbiol. 2003, 69, 1875-1883. [CrossRef] [PubMed]

8. de Azeredo, L.A.I.; Gomes, E.A.T.; Mendonca-Hagler, L.C.; Hagler, A.N. Yeast communities associated with sugarcane in Campos, Rio de Janeiro, Brazil. Int. Microbiol. 1998, 1, 205-208.

9. Glushakova, A.M.; Yurkov, A.M.; Chernov, I.Y. Massive isolation of anamorphous ascomycete yeasts Candida oleophila from plant phyllosphere. Microbiology 2007, 76, 799-803. [CrossRef]

10. Peter, G.; Tornai-Lehoczki, J.; Dlauchy, D. Ogataea allantospora sp. nov., anascomycetous yeast species from phylloplane. Antonie Leeuwenhoek 2007, 92, 443-448. [CrossRef]

11. Slavikova, E.; Vadkertiova, R.; Vranova, D. Yeasts colonizing the leaves of fruit trees. Ann. Microbiol. 2009, 59, 419-424. [CrossRef]

12. Inácio, J.; Portugal, L.; Spencer-Martins, I.; Fonseca, Á. Phylloplane yeasts from Portugal: Seven novel anamorphic species in the Tremellales lineage of the Hymenomycetes (Basidiomycota) producing orange-coloured colonies. FEMS Yeast Res. 2005, 5, 1167-1183. [CrossRef]

13. Nakase, T.; Takashima, M.; Itoh, M.; Fungsin, B.; Potacharoen, W.; Atthasampunna, P.; Komagata, K. Ballistoconidium-forming yeasts found in the phyllosphere of Thailand. Microbiol. Cult. Collect. 2001, 17, 23-33.

14. Santos, A.R.; Faria, E.S.; Lachance, M.A.; Rosa, C.A. Ogataea mangiferae sp. nov., a methylotrophic yeast isolated from mango leaves. Int. J. Syst. Evol. Microbiol. 2015, 65, 1855-1859. [CrossRef] [PubMed]

15. Koowadjanakul, N.; Jindamorakot, S.; Yongmanitchai, W.; Limtong, S. Ogataea phyllophila sp. nov., Candida chumphonensis sp. nov. and Candida mattranensis sp. nov., three methylotrophic yeast species from phylloplane in Thailand. Antonie Leeuwenhoek 2011, 100, 207-217. [CrossRef]

16. Limtong, S.; Kaewwichian, R.; Groenewald, M. Ogataea kanchanaburiensis sp. nov. and Ogataea wangdongensis sp. nov., two novel methylotrophic yeast species from phylloplane in Thailand. Antonie Leeuwenhoek 2013, 103, 551-558. [CrossRef] [PubMed]

17. Limtong, S.; Kaewwichian, R.; Yongmanitchai, W.; Kawasaki, H. Diversity of culturable yeasts in phylloplane of sugarcane in Thailand and their capability to produce indole-3-acetic acid. World J. Microbiol. Biotechnol. 2014, 30, 1785-1796. [CrossRef]

18. Limtong, S.; Kaewwichian, R. Candida phyllophila sp. nov. and Candida vitiphila sp. nov., two novel yeast species from grape phylloplane in Thailand. J. Gen. Appl. Microbiol. 2013, 59, 191-197. [CrossRef] [PubMed]

19. Limtong, S.; Kaewwichian, R. The diversity of culturable yeasts in the phylloplane of rice in Thailand. Ann. Microbiol. 2015, 65, 667-675. [CrossRef]

20. Nasanit, R.; Krataithong, K.; Tantirungkij, M.; Limtong, S. Assessment of epiphytic yeast diversity in rice (Oryza sativa) phyllosphere in Thailand by a culture-independent approach. Antonie Leeuwenhoek 2015, 107, 1475-1490. [CrossRef]

21. Nasanit, R.; Tangwong-o-thai, A.; Tantirungkij, M.; Limtong, S. The assessment of epiphytic yeast diversity in sugarcane phyllosphere in Thailand by culture-independent method. Fungal Biol. 2015, 119, 1145-1157. [CrossRef]

22. Nasanit, R.; Jaibangyang, S.; Tantirungkij, M.; Limtong, S. Yeast diversity and novel yeast D1/D2 sequences from corn phylloplane obtained by a culture-independent approach. Antonie Leeuwenhoek 2016, 109, 1615-1634. [CrossRef]

23. Srisuk, N.; Nutaratat, P.; Surussawadee, J.; Limtong, S. Yeast Communities in Sugarcane Phylloplane. Microbiology (Mosc.) 2019, 88, 353-369. [CrossRef]

24. Yurkov, A.; Inácio, J.; Chernov, I.; Fonseca, Á. Yeast biogeography and the effects of species recognition approaches: The case study of widespread basidiomycetous species from birch forests in Russia. Curr. Microbiol. 2015, 70, 587-601. [CrossRef] [PubMed] 
25. Jumpponen, A.; Jones, K.L. Seasonally dynamic fungal communities in the Quercus macrocarpa phyllosphere differ between urban and nonurban environments. New Phytol. 2010, 186, 496-513. [CrossRef] [PubMed]

26. Glushakova, A.M.; Chernov, I.Y. Seasonal dynamic of the numbers of epiphytic yeast communities. Microbiology 2010, 79, 830-839. [CrossRef]

27. Surussawadee, J.; Jindamorakot, S.; Nakase, T.; Lee, C.F.; Limtong, S. Hannaella phyllophila sp. nov., a novel basidiomycetous yeast species associated with plants in Thailand and Taiwan. Int. J. Syst. Evol. Microbiol. 2015, 65, 2135-2140. [CrossRef]

28. Yurkov, A.M.; Kemler, M.; Begerow, D. Species accumulation curves and incidence-based species richness estimators to appraise the diversity of cultivable yeasts from beech forest soils. PLoS ONE 2011, 6, e23671. [CrossRef]

29. Yurkov, A.M.; Kemler, M.; Begerow, D. Assessment of yeast diversity in soils under different management regimes. Fungal Ecol. 2012, 5, 24-35. [CrossRef]

30. Sampaio, J.P.; Gadanho, M.; Santos, S. Polyphasic taxonomy of the basidiomycetous yeast genus Rhodosporidium: Rhodosporidium kratochvilovae and related anamorphic species. Int. J. Syst. Evol. Microbiol. 2001, 51, 687-697. [CrossRef]

31. Gardes, M.; Bruns, T.D. ITS primers with enhanced specificity for basidiomycetes-application to the identification of mycorrhizae and rusts. Mol. Ecol. 1993, 2, 113-118. [CrossRef]

32. O'Donnell, K. Fusarium and its near relatives. In The Fungal Holomorph, Mitotic, Meiotic and Pleomorphic Speciation in Fungal Systematics; Reynolds, D.R., Taylor, J.W., Eds.; CAB International: Wallingford, UK, 1993; pp. 225-233.

33. Kurtzman, C.P.; Robnett, C.J. Identification and phylogeny of ascomycete yeasts from analysis of nuclear large subunit (26S) ribosomal DNA partial sequences. Antonie Leeuwenhoek 1998, 73, 331-371. [CrossRef]

34. Fell, J.W.; Boekhout, T.; Fonseca, A.; Scorzetti, G.; Statzell-Tallman, A. Biodiversity and systematics of basidiomycetous yeasts as determined by large-subunit rDNA D1/D2 domain sequence analysis. Int. J. Syst. Evol. Microbiol. 2000, 50, 1351-1371. [CrossRef] [PubMed]

35. Edgar, R.C. MUSCLE: Multiple sequence alignment with high accuracy and high throughput. Nucleic Acids Res. 2004, 32, 1792-1797. [CrossRef]

36. Kumar, S.; Stecher, G.; Tamura, K. MEGA7: Molecular evolutionary genetics analysis version 7.0 for bigger datasets. Mol. Biol. Evol. 2016, 33, 1870-1874. [CrossRef] [PubMed]

37. Felsenstein, J. Confidence limits on phylogenies: An approach using the bootstrap. Evolution 1985, 39, 783-791. [CrossRef] [PubMed]

38. Hammer, Ø.; Harper, D.A.T.; Ryan, P.D. PAST: Paleontological statistics software package for education and data analysis. Palaeontol. Electron. 2001, 4, 1-9.

39. Colwell, R.K.; Chao, A.; Gotelli, N.J. Models and estimators linking individual-based and sample-based rarefaction, extrapolation and comparison of assemblages. J. Plant Ecol. 2012, 5, 3-21. [CrossRef]

40. Into, P.; Pontes, A.; Jacques, N.; Casaregola, S.; Limtong, S.; Sampaio, J.P. Papiliotrema plantarum sp. nov., a novel tremellaceous sexual yeast species. Int. J. Syst. Evol. Microbiol. 2018, 68, 1937-1941. [CrossRef]

41. Li, M.X. Studies on Sporobolomycetaceae I. Taxonomy of Bullera. Acta Microbiol. Sin. 1982, 36, 17-25.

42. Nakase, T.; Suzuki, M. Ballistospore-forming yeasts found on the surface of the Japanese rice plants Oryza sativa L. J. Gen. Appl. Microbiol. 1985, 31, 457-474. [CrossRef]

43. Bai, F.Y.; Takashima, M.; Nakase, T. Description of Bullera kunmingensis sp. nov., and clarification of the taxonomic status of Bullera sinensis and its synonyms based on molecular phylogenetic analysis. FEMS Yeast Res. 2001, 1, 103-109. [CrossRef]

44. Hoshino, Y.T.; Matsumoto, N. Changes in fungal community structure in bulk soil and spinach rhizosphere soil after chemical fumigation as revealed by 18 S rDNA PCR-DGGE. Soil Sci. Plant Nutr. 2007, 53, 40-55. [CrossRef]

45. Chou, J.Y.; Chen, H.W.; Lin, C.C.; Wen, Y.D.; Wang, W.L. Yeast diversity associated with the biting midge Forcipomyia taiwana in Taiwan. Nova Hedwigia 2015, 101, 519-527. [CrossRef]

46. Camargo, F.P.; Araujo, A.C.V.; de Moraes, E.M.; Dos Santos, A.C.A. A comparison between cactophilic yeast communities isolated from Cereus hildmannianus and Praecereus euchlorus necrotic cladodes. Fungal Biol. 2016, 120, 1175-1183. [CrossRef] [PubMed] 
47. Khunnamwong, P.; Jindamorakot, S.; Limtong, S. Endophytic yeast diversity in leaf tissue of rice, corn and sugarcane cultivated in Thailand assessed by a culture-dependent approach. Fungal Biol. 2018, 122, 785-799. [CrossRef]

48. Yurkov, A.M.; Vustin, M.M.; Tyaglov, B.V.; Maksimova, I.A.; Sineokiy, S.P. Pigmented basidiomycetous yeasts are a promising source of carotenoids and ubiquinone Q10. Microbiology 2008, 77, 1-6. [CrossRef]

49. Morita, T.; Ogura, Y.; Takashima, M.; Hirose, N.; Fukuoka, T.; Imura, T.; Kondo, Y.; Kitamoto, D. Isolation of Pseudozyma churashimaensis sp. nov., a novel ustilaginomycetous yeast species as a producer of glycolipid biosurfactants, mannosyl erythritol lipids. J. Biosci. Bioeng. 2011, 112, 137-144. [CrossRef]

50. Yurkov, A.M.; Röhl, O.; Pontes, A.; Carvalho, C.; Maldonado, C.; Sampaio, J.P. Local climatic conditions constrain soil yeast diversity patterns in Mediterranean forests, woodlands and scrub biome. FEMS Yeast Res. 2016, 16, fov103. [CrossRef]

51. Liu, X.Y.; Chi, Z.; Liu, G.L.; Madzak, C.; Chi, Z.M. Both decrease in ACL1 gene expression and increase in ICL1 gene expression in marine-derived yeast Yarrowia lipolytica expressing INU1 gene enhance citric acid production from inulin. Mar. Biotechnol. 2013, 15, 26-36. [CrossRef]

52. Wu, J.; Hu, J.; Zhao, S.; He, M.; Hu, G.; Ge, X.; Peng, N. Single-cell protein and xylitol production by a novel yeast strain Candida intermedia FL023 from lignocellulosic hydrolysates and xylose. Appl. Biochem. Biotechnol. 2018, 185, 163-178. [CrossRef]

53. Rachamontree, P.; Phusantisampan, T.; Woravutthikul, N.; Pornwongthong, P.; Sriariyanun, M. Selection of Pichia kudriavzevii Strain for the Production of Single-Cell Protein from Cassava Processing Waste. World Acad. Sci. Eng. Technol. Int. J. Biol. Food Veter. Agric. Eng. 2015, 9, 460-464.

54. Robak, K.; Balcerek, M. Review of second generation bioethanol production from residual biomass. Food Technol. Biotechnol. 2018, 56, 174. [CrossRef] [PubMed]

55. Yuangsaard, N.; Yongmanitchai, W.; Yamada, M.; Limtong, S. Selection and characterization of a newly isolated thermotolerant Pichia kudriavzevii strain for ethanol production at high temperature from cassava starch hydrolysate. Antonie Leeuwenhoek 2013, 103, 577-588. [CrossRef] [PubMed]

56. Li, M.; Liu, G.L.; Chi, Z.; Chi, Z.M. Single cell oil production from hydrolysate of cassava starch by marine-derived yeast Rhodotorula mucilaginosa TJY15a. Biomass Bioenerg. 2010, 34, 101-107. [CrossRef]

57. Poontawee, R.; Yongmanitchai, W.; Limtong, S. Efficient oleaginous yeasts for lipid production from lignocellulosic sugars and effects of lignocellulose degradation compounds on growth and lipid production. Process Biochem. 2017, 53, 44-60. [CrossRef]

58. Matsui, T.; Otsuka, K.Y.; Sato, S. Microbial oil production from carbohydrates using Sporobolomyces carnicolor strain O33. Ann. Microbiol. 2012, 62, 861-864. [CrossRef]

59. Nutaratat, P.; Amsri, W.; Srisuk, N.; Arunrattiyakorn, P.; Limtong, S. Indole-3-acetic acid production by newly isolated red yeast Rhodosporidium paludigenum. J. Gen. Appl. Microbiol. 2015, 61, 1-9. [CrossRef]

60. Levinson, W.E.; Kurtzman, C.P.; Kuo, T.M. Production of itaconic acid by Pseudozyma antarctica NRRL Y-7808 under nitrogen-limited growth conditions. Enzym. Microb. Technol. 2006, 39, 824-827. [CrossRef]

61. Do, D.T.H.; Theron, C.W.; Fickers, P. Organic Wastes as Feedstocks for Non-Conventional Yeast-Based Bioprocesses. Microorganisms 2019, 7, 229. [CrossRef]

62. Carneiro, C.V.G.; de Paula e Silva, F.C.; Almeida, J.R. Xylitol Production: Identification and Comparison of New Producing Yeasts. Microorganisms 2019, 7, 484. [CrossRef]

63. Tomaszewska, L.; Rywińska, A.; Gładkowski, W. Production of erythritol and mannitol by Yarrowia lipolytica yeast in media containing glycerol. J. Ind. Microbiol. Biotechnol. 2012, 39, 1333-1343. [CrossRef]

64. Trichez, D.; Steindorff, A.S.; Soares1, C.E.V.F.; Formighieri, E.F.; Almeida, J.R.M. Physiological and comparative genomic analysis of new isolated 2 yeasts Spathaspora sp. JA1 and Meyerozyma caribbica JA9 reveal 3 insights into xylitol production. FEMS Yeast Res. 2019, 19, foz034. [CrossRef] [PubMed]

65. Stratilová, B.; Klaudiny, J.; Řehulka, P.; Stratilová, E.; Mészárosová, C.; Garajová, S.; Pavlatovská, B.; Řehulková, H.; Kozmon, S.; Šesták, S.; et al. Characterization of a long-chain $\alpha$-galactosidase from Papiliotrema flavescens. World J. Microbiol. Biotechnol. 2018, 34, 19. [CrossRef] [PubMed]

(C) 2020 by the authors. Licensee MDPI, Basel, Switzerland. This article is an open access article distributed under the terms and conditions of the Creative Commons Attribution (CC BY) license (http://creativecommons.org/licenses/by/4.0/). 